\title{
Pat Croskerry, Karen S. Crosby, Stephen M. Schenkel, Robert L. Wears (eds): Patient safety in emergency medicine
}

\author{
Lippincott Williams \& Wilkins, a Wolters Kluver Company, Philadelphia, Baltimore, \\ New York, London, Buenos Aires, Hong Kong, Sydney, Tokyo, 2008, 448 pp, Hardcover, \\ 99,95 US\$, ISBN: 978-0-7817-7727-8
}

Jean-Yves Jenny

Received: 20 December 2010/ Accepted: 21 December 2010/Published online: 6 January 2011

(c) Springer-Verlag 2011

Patient safety is one of the key points of the current medical practice. However, its definition is still controversial. This book deals with the general definitions and content of patient safety. It is mainly dedicated to emergency care units, but the authors expect to give relevant information to every practitioner, whatever field of interest.

The first sections deal with organizational questions to improve safety. It is clearly stated that the understanding of successes and failures is mandatory, and incident monitoring must be organized in an optimal way to allow effective feedback. The desired organization of an emergency unit is analyzed, on the architectural point of view as well as medical organization, communication between the members of the team, optimization of human performance, and educating staff and patients. An interesting section deals with the role of the chair of such units.

Even if emergency medicine is a very specialized field with less involvement of the orthopedic surgeons, they will still find some interesting and relevant information for their daily activity.

Conflict of interest No funds were received in support of this study. 